\title{
Valve Stiction Detection and Quantification Using K-means Clustering Based Moving Window
}

\author{
Approach
}

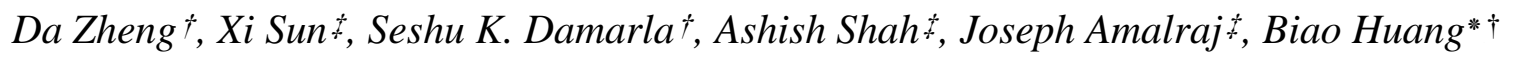

$\dagger$ Department of Chemical and Materials Engineering, University of Alberta, Edmonton-T6G 2G6, Alberta, Canada

¥Syncrude Canada Limited, Fort McMurray, Alberta, Canada - T9H 3L1

*E-mail: bhuang@ualberta.ca 

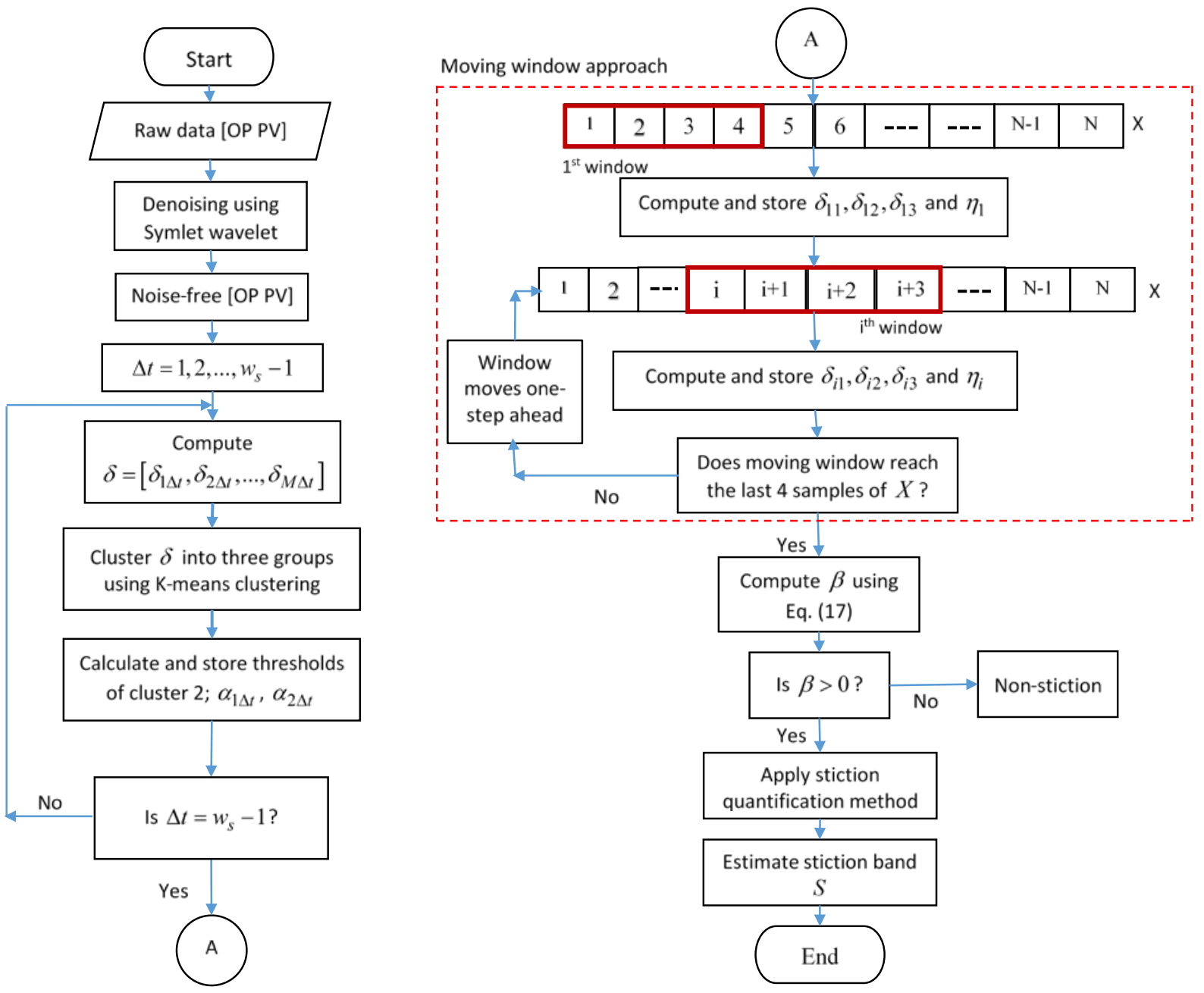

Figure S1. Flowchart of proposed method 

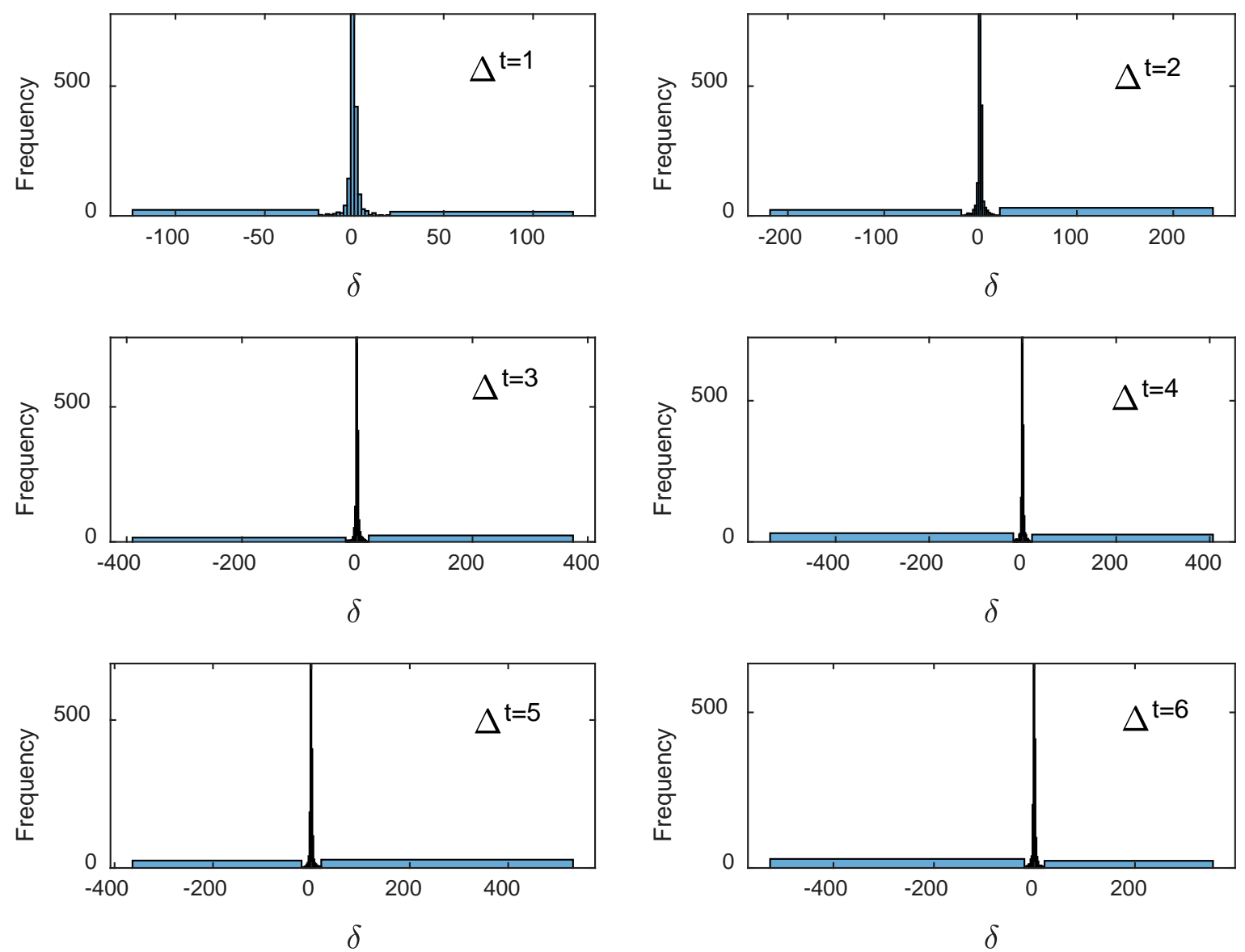

Figure S2. Distribution of $\delta$ for different step sizes

Table S1. Analysis of obtained clusters

\begin{tabular}{|c|c|c|c|c|c|c|c|}
\hline \multirow{2}{*}{$\Delta t$} & \multicolumn{2}{|c|}{$\delta$} & \multicolumn{3}{c|}{ Centers } & \multicolumn{2}{c|}{ Thresholds of cluster 2 } \\
\cline { 2 - 8 } & Min. & Max. & Cluster 1 & Cluster 2 & Cluster 3 & $\alpha_{1}$ & $\alpha_{2}$ \\
\hline 1 & -124.01 & 122.33 & -60.34 & -0.45 & 44.96 & -19.89 & 19.01 \\
\hline 2 & -218.45 & 241.26 & -69.17 & -0.40 & 67.63 & -19.07 & 18.90 \\
\hline 3 & -389.90 & 374.43 & -126.69 & -0.30 & 75.01 & -18.80 & 19.12 \\
\hline 4 & -540.20 & 406.98 & -53.61 & -0.39 & 83.25 & -19.69 & 19.89 \\
\hline 5 & -363.55 & 531.72 & -63.54 & 0.23 & 91.22 & -18.64 & 18.88 \\
\hline 6 & -526.04 & 355.21 & -68.35 & -0.47 & 60.90 & -19.75 & 19.77 \\
\hline
\end{tabular}

